\title{
O CINEMA COMO SÍMBOLO DA MODERNIDA- DE EM TERESINA (1900-1920)
}

\section{CINEMA AS A SYMBOL OF MODERNITY IN TE- RESINA (1900-1920)}

Isaac Peron Cunha Carvalho ${ }^{1}$

Resumo: O presente trabalho Roberto lobato e Michel de Certem por objetivo a análise do cinema como símbolo da modernidade em Teresina, Piauí de 1900 a 1920, com destaque para o estudo da conjuntura em que a cidade estava passando na época, que passava por diversas transformações, tanto cotidianas, como sociais e econômicas, com a inserção na sociedade de diversas inovações tecnológicas, estabelecendo relações imediatas, com as grandes cidades. Dessa forma, foram utilizados textos historioteau, também foram utilizados textos que elucidam acerca do processo de modernização como os textos de Nicolau Sevcenko, Francisco Alcides do Nascimento e de Teresinha Queiroz, eles também puderam ser utilizados como forma de percepção das representações sociais acerca do cinema na cidade.

Palavras-chave: História; cinema; cidade; modernidade; Teresina.

gráficos que explicam o conceito de cidade, como a própria Raquel Abstract: This paper aims to Rolnik, Sandra Jatahy Pesavento, analyze the cinema as a symbol 1 Licenciatura em História pela UFPI

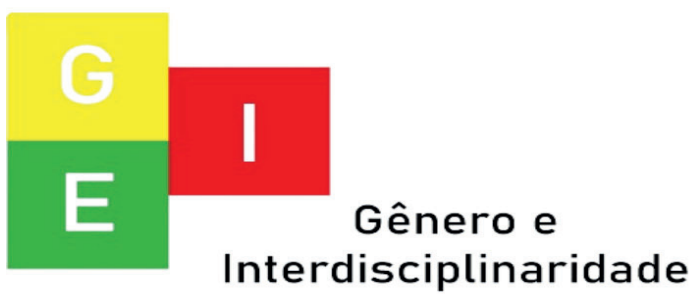


Vol. 02 - n 06 - ano 2021

Editora Acadêmica Periodicojs

of modernity in Teresina, Piauí

from 1900 to 1920 , with empha-

O século XIX, foi um sis on the study of the context in which the city was going through at the time, which underwent several transformations, both daily, as social and economic, with the insertion in society of several technological innovations, establishing immediate relations with the big cities. In this way, historiographic texts that explain the concept of city were used, such as Raquel Rolnik, Sandra Jatahy Pesavento, Roberto Lobato and Michel de Certeau. Also used were texts that elucidate about the modernization process, such as the texts by Nicolau Sevcenko, Francisco Alcides do Nascimento, and Teresinha Queiroz.

Keywords: History; cinema; city; modernity; Teresina.

\section{Introdução}

século de muitas mudanças, tanto sociais como culturais, no qual se desenvolveram e se firmaram muitas disciplinas, até mesmo a própria área da História passava por transformações, abrindo-se a novas problemáticas e novas áreas de pesquisa. A própria fundação da Escola dos Annales é um exemplo dessa abertura, de interdisciplinaridade. Tendo por base a autora Teresinha Queiroz em seu livro Os literatos e a República: Clodoaldo Freitas, Higino Cunha e as tiranias do tempo, que até a primeira guerra mundial havia pequenos surtos de invenções, após este "trauma mundial, emerge dele o mundo da máquina, incorporado e aceito como tal. As máquinas, os inventos e os automóveis já faziam parte do cotidiano de muitos." (2011, p. 35).Sem contar que esta

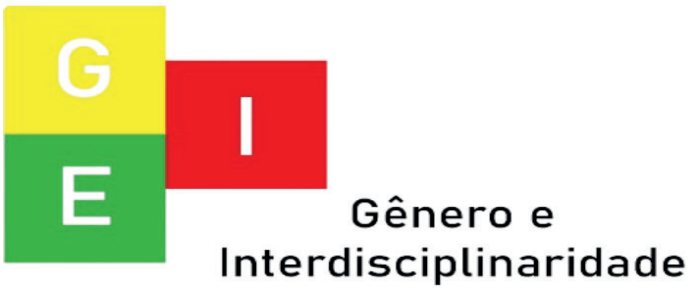


Vol. 02 - n 06 - ano 2021

Editora Acadêmica Periodicojs

era uma sociedade agrária e ru-

ral, que ainda estava dando seus

primeiros passos rumo à modernização e progresso.

Dessa forma, este trabalho faz um estudo acerca do processo de modernização, e os seus símbolos, tendo como analise a chegada do cinema e seus impactos na sociedade de Teresina. Ao mesmo tempo em que está se inseria no processo descrito, também não se pode deixar de conceituar a cidade, explicitado e debatido por diversos autores em alguns textos, Pesavento (2009), que em seu artigo Cidades visíveis, cidades sensíveis, cidades imaginárias, apresenta um conceito interessante acerca da cidade:

Ela era o território onde se realizava um processo de produção do capital e onde se produziam as relações capitalistas e, por força da opção teórica, onde se enfrentavam as classes sociais e podia apreciar o processo de dominação/subordinação em curso (2007, p.13).

Vê-se, que para essa autora, o conceito de cidade é muito geral, deve ser pensado como um lugar de embate, de produção e transformação, ocasionadas pelo o próprio ser humano, ela não é mais apenas como um lócus privilegiados, mas sim "um objeto de reflexão, a partir das representações sociais que produz e que se objetivam em práticas sociais" (PESAVENTO,2007, p.13).

Queiroz (2011) traz uma ampla visão de como era Teresina no final do século XIX e no decorrer do século XX:

$O$ crescimento demográfico de Teresina entre 1872 e 1940 não é dos mais acentuados e não al-

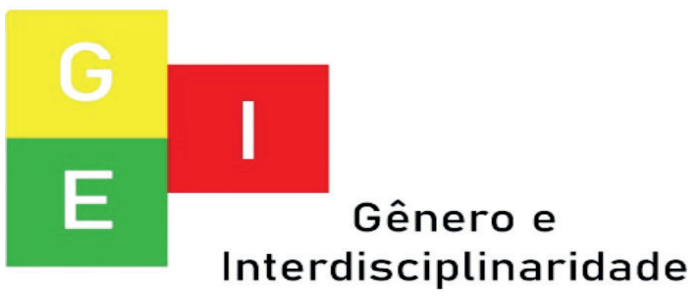


ISSN: 2675-7451

Vol. 02 - n 06 - ano 2021

Editora Acadêmica Periodicojs

cança sequer a média do Estado no mesmo período. Rarefação demográfica, emigração e nenhuma imigração estrangeira, esse e o quadro do Piauí no Período. Entretanto, um estudo detalhado da população de todos os seus municípios mostrou que certos arranjos estão se processando ao longo do seu território, reorganizando-se a população e adensando-se no sentido das margens do rio Parnaíba e do norte do Estado, num movimento que favorece Teresina, em vista de sua localização. (QUEIROZ, 2011, p. 19)

de acordo com a autora "essas alterações se explicam pelo o rearranjo das atividades econômicas e pela inflexão que vai ter a economia do Estado a partir da passagem do século, quando vem a centrar-se no extrativismo. " (QUEIROZ, 2011, p. 19), mas o que permitirá o desenvolvimento do Estado, será: A mudança da capital de Oeiras para Teresina e o incremento da navegação a vapor eram tidas como condições fundamentais pelos os homens públicos para o desenvolvimento da província e para a independência do seu comercio em relação ao Maranhão. Essas medidas deveriam ser complementadas com a abertura de estradas de rodagem ligando as regiões produtoras aos portos fluviais. (QUEIROZ, 2011, p. 21)

Pois a partir disso "é possível afirmar que, durante a segunda metade do século XIX, as iniciativas públicas visavam

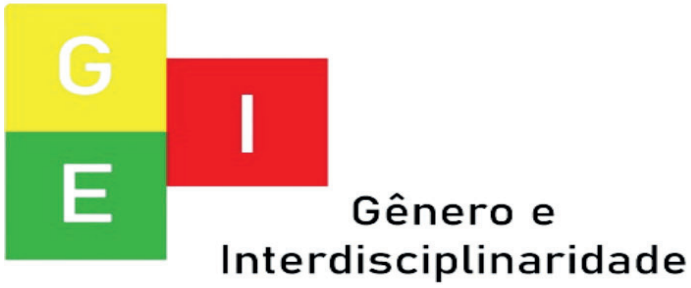


ISSN: 2675-7451

Vol. 02 - n 06 - ano 2021

Editora Acadêmica Periodicojs

a romper o isolamento da Província, integrando-a ao espaço regional e que, neste século, a expansão pretendida abarca $\mathrm{o}$ mundo capitalista. " (QUEIROZ, 2011, p. 21) .No entanto o movimento de integração através das vias fluviais só se verá em plena atividade em 1908, caracterizado pela autora como sendo muito rápido, porque "em que pese o aspecto acanhado e o crescimento não intempestivo, buscavam aprofundar as ligações do universo regional como forma de superar as limitações do mesmo.” (QUEIROZ, 2011, p. 23). E a partir dessa necessidade de desenvolver a economia piauiense, que diversas obras vão ser feitas com o intuito de um comercio de exportação.

\section{A cidade como palco das ino-} vações do século XIX
No entanto, este espaço está sujeito a sofrer também diversos processos, dos quais muitos só têm um único intuito, o de privilegiar uma certa classe, que possui os meios de produção, os melhores bairros e as melhores casas. Isto muitas vezes é possibilitado pela própria urbanização e modernização, que começa a partir do século XIX, com o crescimento e a proliferação de diversas cidades.

Este mesmo processo que será impulsionado pela revolução industrial, que se caracterizou principalmente pela mudança nos meios de produção. Isto não foi diferente no resto do mundo, até mesmo em Teresina, a capital do Piauí. Contudo a cidade é também espaço de sensibilidade, mas esta é apenas imaginária, trata-se de uma construção do pensamento humano, em que também está situada num tempo e num espa-

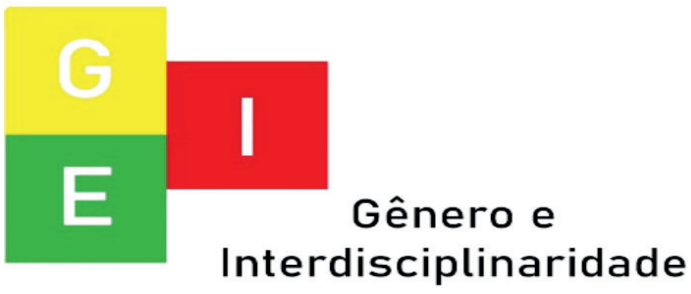


ISSN: 2675-7451

Vol. 02 - n 06 - ano 2021

Editora Acadêmica Periodicojs

ço, "nesse processo imaginário de construção de espaço-tempo, na invenção de um passado e de um futuro, a cidade está sempre a explicar o seu presente" (PESAVENTO,2007, p.17). Com isso há uma definição de identidade, que nos dá uma sensação de pertencimento a determinado lugar.

Uma outra análise a respeito do referido processo é da autora Raquel de Rolnik, em seu livro O que é cidade. Neste livro, ela discute a cidade se utilizando de São Paulo como exemplo, mas não e somente isto que me interessa, mais sim a sua outra análise em referência a ocupação do espaço pela sociedade e que está por sua vez relaciona-se com o surgimento das primeiras cidades, mas que o lugar ocupado tinha uma relação fundamental com a divisão do trabalho, a classe social de cada um, mas, ao mesmo tempo, cada um exercia sua participação política, ainda que fosse através da submissão.

Encontra-se aqui o motivo de chamar a cidade de $\mathrm{Ci}$ vitas, como menção à cidade Romana, em que o conceito de cidade estava relacionado, sobretudo, a uma instância política. Da necessidade de organização da vida pública, na cidade, emerge um poder urbano, autoridade político administrativa encarregada de sua gestão, sua primeira forma na história da cidade é a de um poder altamente centralizado e despótico: "a realeza" (ROLNIK, 1995, p. 20).

$\mathrm{Na}$ segunda parte de seu livro, a autora fala sobre as cidades capitalistas e as suas características, que serão marcadas inicialmente por um destaque ás atividades mercantis. Ao longo do texto ela vai discorrer em diversos tópicos, como, por exemplo, "O ar da cidade liber-

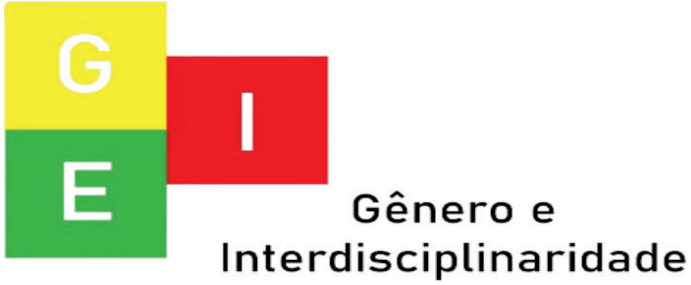


ISSN: 2675-7451

Vol. 02 - n 06 - ano 2021

Editora Acadêmica Periodicojs

ta”. Nesta parte a autora expõe o sentimento e também o novo sentido que esse novo ambiente expressara, por conta da produção de excedentes; isto transformara as relações entre o campo e a cidade.

é a partir de um certo momento da história que as cidades passam a se organizar em função do mercado, gerando um tipo de estrutura urbana que não só opera uma reorganização do seu espaço interno , mas também redefine todo o espaço circundante, atraindo para a cidade grandes populações. (ROLNIK, 1995, p. 30).

No decorrer do texto, ela fala acerca dos meios de produção e em como os detentores destes meios mudam toda a organização da cidade:

a organização da cidade passa a ser marcada pela divisão da sociedade em classes: de um lado os proprietários dos meios de produção, os ricos e detentores do dinheiro e bens; de outro, os vendedores de sua força de trabalho, os livres e despossuídos. (ROLNIK, 1995, p. 39).

Já na visão de Norberto Lobato de Corrêa, este aborda a temática de cidade um pouco diferente, "O geógrafo considera a cidade, de um lado como um ou vários núcleos localizados em uma região ou pais de outro, a cidade é considerada como espaço urbano, sendo analisada a partir de mapas de grande escala" (CORRÊA, 1989, p. 5) para esse autor diferentemente de Ronik(1995), o autor situa o conceito de cidade mais na cidade capitalista, dizendo ,como tal, que o:

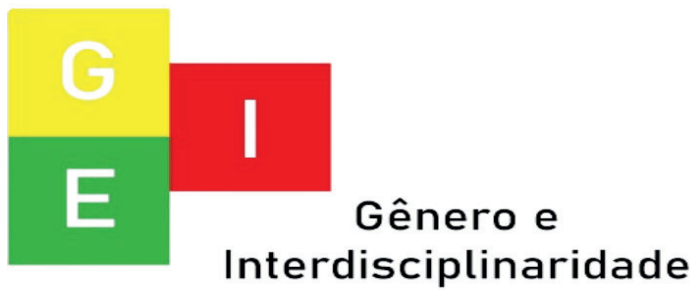


Vol. 02 - n 06 - ano 2021

Editora Acadêmica Periodicojs

O espaço de uma grande cidade capitalista constitui-se, em um primeiro momento de sua apreensão, no conjunto de diferentes usos da terra justapostos entre si. Tais usos definem áreas, como o centro da cidade, local de concentração de atividades comerciais, de serviços e de gestão, áreas industriais , áreas residenciais distintas em termos de forma e conteúdo social, de lazer e, entre outras, aquelas de reserva para a futura expansão (CORRÊA, 1989, p. 7).

Ele analisa também as relações capitalistas e como estas se manifestam "através das relações espaciais envolvendo a circulação de decisões e investimentos de capital, mais-valia, salários, juros, rendas, envolven- do ainda a pratica do poder e da ideologia" (CORRÊA, 1989, p. 8) .Outro autor que faz referência à temática de cidade é Michel de Certeau, Em seu livro A Invenção do Cotidiano Artes de Fazer , em que o autor nos traz uma nova abordagem, pois este centra o seu foco de análise não mais somente na cidade, mais sim nas relações sociais, porque para ele são as mesmas que determinam o indivíduo e não o seu inverso. Por isso, só se pode apreendê-lo a partir de suas práticas sociais. Por meio de sua análise percebe o autor a sensibilidade e a individualidade como o local onde se organiza, às vezes de modo desconexo e contraditório, a pluralidade da vivência social.

\section{O caráter excludente da mo- dernização em Teresina}

O conceito de moderni-

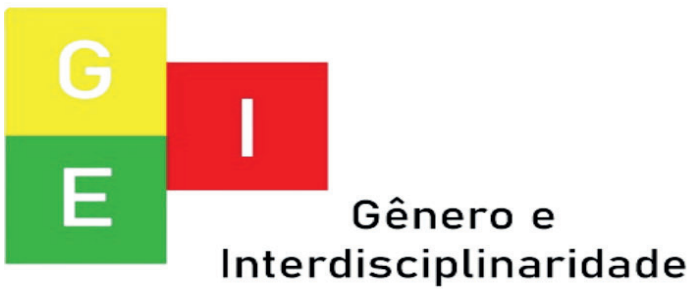


ISSN: $2675-7451$

Vol. 02 - n 06 - ano 2021

Editora Acadêmica Periodicojs

dade muitas vezes, encontra-se atrelado a uma construção do futuro, por meio de projetos e visões de mundo, e este geralmente é influenciado por um ideário de cidade europeu "planos e utopias construídas sobre o futuro da cidade, inscrevendo uma cidade sonhada e desejada em projetos urbanísticos" (PESAVENTO, 2007, p. 17),percebe-se que o conceito de modernidade seria uma projeção para o futuro e que ,muitas vezes e imposta de forma autoritária, como aconteceu em diversas cidades do Brasil.

No livro "cidades sob o fogo" o autor mostra as várias faces desse processo de modernização nas cidades brasileiras, especificamente isto em Teresina, aliando sempre com o contexto histórico do Brasil República, além de fazer uma análise sobre os impactos deste, nas parcelas mais pobres, deixando a seguinte pergunta no início: A modernização das cidades brasileiras serviu para que proposito? E a quem beneficiou esta modernização? Esta e diversas outras perguntas são respondidas no decorrer de sua leitura. De acordo com o professor Dr. Alcides Nascimento:

No Brasil, as reformas urbanas levadas a cabo no período republicano tiveram caráter autoritário. Os segmentos sociais menos privilegiados economicamente para as periferias das cidades, da mesma forma como aconteceu com São Paulo, ou ocuparam os morros no Rio de Janeiro. Em Teresina, aqueles que não podiam construir casas e cobri-las de telhas foram obrigados a morar fora da área urbana. (NASCIMENTO, 2015, pp. 37 - 38)

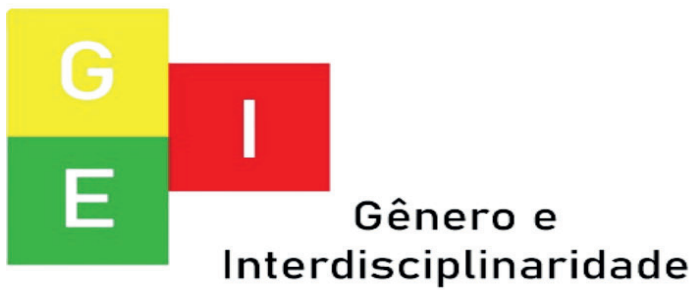


ISSN: 2675-7451

Vol. 02 - n 06 - ano 2021

Editora Acadêmica Periodicojs

O caráter excludente

do processo de modernização possui várias faces, tanto que, ao longo de seu livro são explicitadas várias passagens acerca das intenções modernizadoras, e como também será construído um discurso em cima disso, e estes mesmos discursos aliados com alguns acontecimentos importantes traduzirão a ideia de progresso.

Havia um ideal a que se queria chegar de modelo de cidade, um exemplo seria as próprias obras que serão feitas pelos os governantes com o intuito de embelezamento e urbanização na cidade de Teresina, inclusive em seu artigo, em que o autor se refere:

Ademais desenvolve-se no o texto na perspectiva de que o espaço físico e as culturas são elementos constitutivos da vida dos moradores da cidade. Verifica-se a relação dos habitantes com as configurações físicas e imaginarias e reflete-se a relação dos habitantes com a configurações físicas e imaginárias e reflete-se sobre como constroem, ocupam, usam e disputam lugares, dando sentido a eles, projetando sonhos, vivendo carências no alinhavar de uma trama de costumes, tradições e crenças, hábitos, códigos, normas, politicas, condições de lugar, rotinas, memorias inscritas no traçado, na paisagem da cidade e no imaginário dos moradores. As crônicas, neste caso, são fontes privilegiadas de informações para o pesquisador. (NASCIMENTO, 2007, pp. 196 - 197).

Um dos pontos primor-

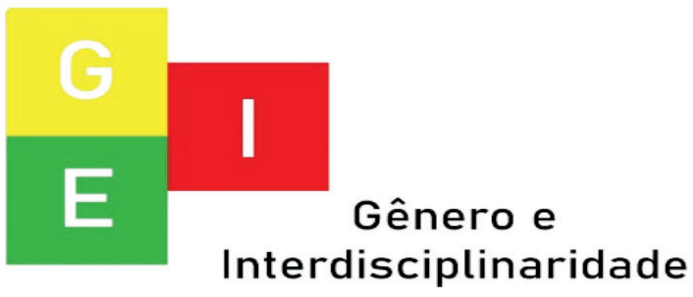


ISSN: 2675-7451

Vol. 02 - n 06 - ano 2021

Editora Acadêmica Periodicojs

diais analisados por esse artigo e que não pode ser deixado de lado é o de como se deu, e em quais circunstâncias a modernização ocorreu. Um trecho que explicita bem como era a capital do Piauí na primeira década do século $X X$ é umas das passagens do livro A cidade sob o fogo: modernização e violência policial em Teresina (1937-1945), professor Dr. Alcides Nascimento:

A cidade, até o início da primeira década do século $\mathrm{XX}$, tinha aquele aspecto bem característico das cidades coloniais. "Ralamente habitada, as ruas estreitas, a sujeira e a presença de animais eram comuns. A maioria da população ocupava construções "acanhadas" e "miseráveis": “ as residências nobres e os prédios oficiais opulentos e sólidos davam a dimensão do contraste com as casas dos moradores pobres. "Não apresen- tava nenhum sinal urbano que a definisse como uma cidade moderna: "Ausência total e absoluta de calçamento, água tratada e canalizada, transporte público, luz elétrica, esgoto, telefone etc. (NASCIMENTO, 2015, p. 127). A partir do trecho explicitado, é possível perceber que “ a realidade de Teresina não era muito diferente das demais cidades do Nordeste" (NASCIMENTO, 2015, p. 128), mais também “existiam as pretensões modernizadoras e própria elite política e intelectual que residia na cidade construiu um discurso de modernização" (NASCIMENTO, 2015, p. 128). Isto se deu pelo o simples fato de que "a cidade foi construída com a finalidade de ser a capital da província do Piauí: portanto marcada para uma vocação urbana." (NASCIMENTO, 2015, p. 128). É algo inegável, pois para que outro fundamento serviria

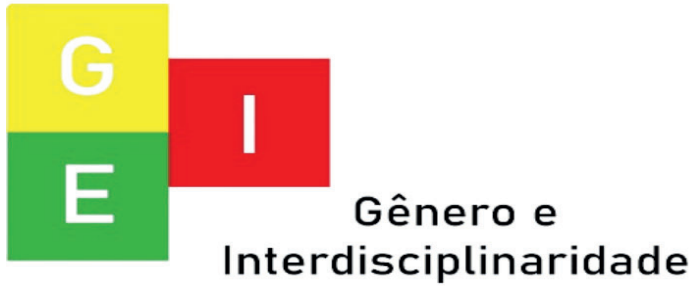


ISSN: 2675-7451

Vol. 02 - n 06 - ano 2021

Editora Acadêmica Periodicojs

uma capital? Assim, a cidade é um fenômeno que se revela pela percepção de emoções e sentimentos dados pelo viver urbano e também pela expressão de utopias, de esperanças, de desejos e medos, individuais e coletivos, que esse habitar em proximidade propicia. ” (PESAVENTO, 2007, p. 14).

Mais sobretudo, "os governantes piauienses incorporaram a ideia do novo como sinônimo de moderno e voltaram as suas vistas para a cidade que concentrava as ações políticos-administrativas" (NASCIMENTO, 2015, p. 329).e à medida que “o progresso foi invadindo o Pais, a cidade foi integrada as demais regiões por transportes mais rápidos - avião, caminhões e trens" (NASCIMENTO, 2015, p. 329). tanto é que a própria Teresina estará situada nesse processo , através não somente da inserção

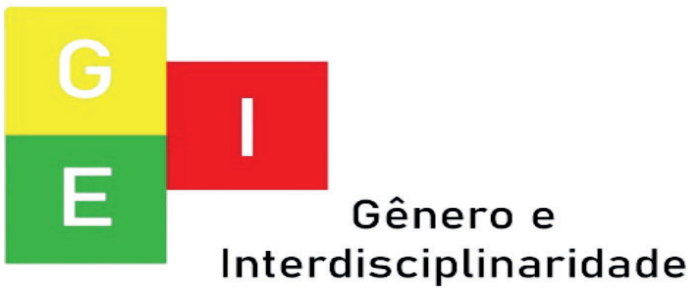


ISSN: 2675-7451

Vol. 02 - n 06 - ano 2021

Editora Acadêmica Periodicojs

microscópico, as alterações sociais ocorriam, afetando o modus vivendi da população e da cidade. "(QUEIROZ, 2011, p. 34). E por meio dessas transformações, com a inserção de diversos inventos da época, que o cinema se insere, como uma diversão nova, um lazer que impressiona, emociona e ao mesmo tempo muda as práticas de uma determinada sociedade

Diversas dúvidas e perguntas rondavam-me como, por exemplo como ás pessoas reagiram as primeiras projeções do cinematografo, seja no mundo ou seja em Teresina? Tiveram mais opiniões positivas ou negativas? E como este havia alterado as práticas de sociabilidade, numa sociedade que passava por diversas mudanças? Não se incomode, pois, e disso que será tratado a partir de agora.

\section{O cinema como símbolo da mo- dernidade em Teresina (1900 - 1920)}

Além desses diversos pontos que foram abordados até aqui, o intuito desse artigo não e somente analisar o conceito de cidade e o de modernização, mas sim também analisar o cinema, como símbolo da modernidade, ou seja, optou-se por partir a analise acerca do cotidiano.

Como esta sociedade em mudança recebeu o conjunto dessas transformações, ou seja se privilegiou-se as novas formas de relações sociais, que o cinema introduziu com o advento da modernidade nos anos de sua chegada até a sua expansão, se constituindo como uma das diversões que havia na capital, além do teatro, da música, e outras formas de diversões do recorte temporal abordado, um

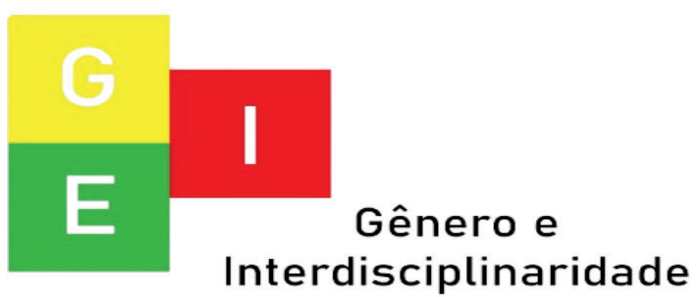


ISSN: 2675-7451

Vol. 02 - n 06 - ano 2021

Editora Acadêmica Periodicojs

autor que nos traz um importante analise a respeito do século que ocorreu a invenção do cinema, e o Nicolau Sevcenko:

O século XIX foi um período de avanços científicos prodigiosos, durante o qual campos completamente novos da ciência surgiram [...]. O desenvolvimento tecnológico foi também espetacular - talvez mais que o científico na mente do grande público. Transporte, eletrificação, indústrias químicas, controle de doenças [...] estavam alterando a sociedade de modo [...] irreversível. Por volta de 1900 o poder da tecnologia estava muito além do que qualquer outro século jamais sonhara. Não havia precedente histórico para o que se passava.... Isso suscitou um otimismo curioso, uma fé que afirmava com efeito que estávamos no caminho certo....... (SEVCENKO, 1998, p. 514)

Através dessa passagem e possível observar, como foi, a efervescência causada pelas inovações surgidas a partir do poder do conhecimento, pois havia um ideal utópico que este mesmo poder, poderia resolver todos os problemas, e até mesmo nos levar a novos mundos. Outro fato importante de ser mencionado e acerca de que a inserção de “ novos recursos técnicos, por suas características mesmo, desorientam, intimidam, perturbam, confundem, distorcem e alucinam." (SEVCENKO, 1998, p. 516),sem contar que "nem todas essas formas de lazer eram novas, novo era o sentido que lhes é atribuído, nova e a sua condição

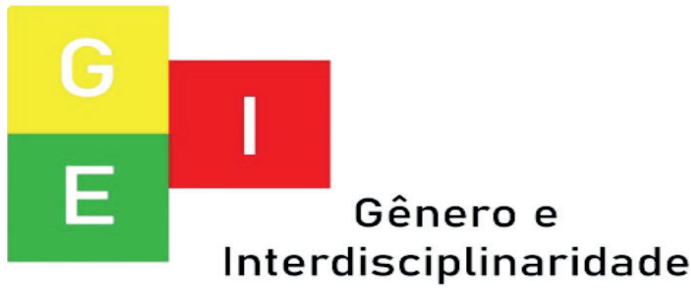


ISSN: 2675-7451

Vol. 02 - n 06 - ano 2021

Editora Acadêmica Periodicojs

de veículo civilizador e moder-

nizador, novos são os conteúdos

culturais que elas incorporam. (QUEIROZ, 2011, p. 34).

E não somente isto pois os “ próprios escritores do século XIX, já eram adultos quando viveram as suas primeiras experiências, como a própria exibição do cinema, as viagens de trens e outras mais, enquanto que " as gerações posteriores já nasceram após a consolidação desse processo e portanto foram acostumados desde pequenos a experiência das velocidades tecnológicas." (SEVCENKO, 1998, p. 517), um exemplo disso, seria as próprias crianças de hoje em dia, que já nascem sabendo mexer em aparelhos eletrônicos, enquanto as gerações passadas sentem uma certa dificuldade em se adaptarem as novas tecnologias.

No entanto, a autora já citada, retrata bem como foi o contexto da chegada do cinema e as primeiras projeções no Theatro 4 de setembro, este se deu "na passagem do século, mais precisamente nos anos finais do século XIX e nos primeiros anos do século $\mathrm{XX}$, foi que as novidades modernas e a estupefação face a elas se fizeram mais presente em Teresina. " (QUEIROZ, 2011, p. 34).

Em 4 de setembro de 1902, achava-se em Caxias (Maranhão) o Sr. Bernhard Bluhm, com um cinematógrafo, com a intenção de vir a Teresina exibir o aparelho e sua "excelente coleção de vistas móveis e fixas". A 26 estava em Teresina e a 27 deveria exibi-lo no Theatro 4 de setembro, executando um programa variado e atraente". (QUEIROZ, 2011, p. 45)

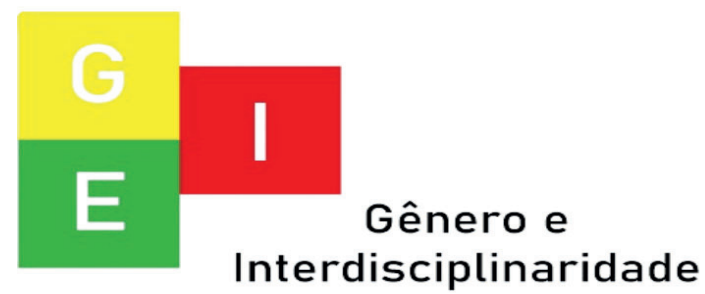


ISSN: 2675-7451

Vol. 02 - n 06 - ano 2021

Editora Acadêmica Periodicojs

Em outra passagem a

autora, explicita como "o progresso, materializado em inúmeras inovações utilitárias $\neg-$ que, embora fossem apropriadas pela grande maioria da população, não deixavam de indicar os novos rumos e promessas da civilização.” (QUEIROZ, 2011, p. 34). Tanto "que umas das primeiras apresentações de imagens em movimento na Europa ocorreu com a exibição do filme $\mathrm{A}$ chegada do trem a estação, de Louis Lumiere, em 1895.” (SEVCENKO, 1998, p. 517),e como o próprio autor mostra, as primeira projeção de cinema através de relatos, estas não lotaram muito, mais logo em seguida o invento dos irmãos Lumiere, começa a ganhar popularidade:

Quando houve o anuncio da primeira sessão de cinema, o desinteresse foi completo, os partici- pantes do Congresso reagiram com ceticismo e pouco-caso a suposta "novidade". Apenas 33 gatos-pingados tomaram assento no salão para conferir a engenhoca. Quando a luz se apagou a imagem do trem se pôs em movimento, o resultado foi conforme o relato do escritor russo. Após a projeção os expectadores saíram comentado sua experiência e, em breve, o salão Lumiere estava completamente lotado. (SEVCENKO, 1998, p. 517)

Contudo e importante ressaltar, que em seu outro livro História, Literatura, Sociabilidades a autora Teresinha Queiroz, diz que a " sua sedução deriva do encontro da ciência e da tecnologia com o encantamento pelo o novo e de um surpreender pela

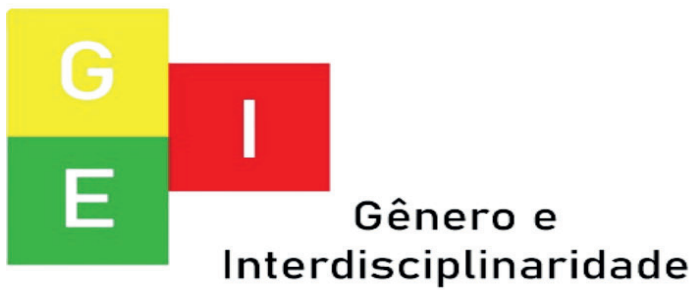


ISSN: 2675-7451

Vol. 02 - n 06 - ano 2021

Editora Acadêmica Periodicojs

ilimitabilidade humana na criação de artefatos os mais diversos e complicados." (2015, p. 208),ou seja ,o cinema e uma arte que une várias outras artes, como o próprio teatro , a música, e os consegue condensar em algo novo, que muitas vezes surpreende de uma forma totalmente inesperada.

Num âmbito geral, o cinema se situa "como componente central desse universo, em expansão, vem a ser a manifestação principal do capitalismo no campo do lazer, que acentua e permite o crescimento cada vez maior de acumulação de capital nos países europeus e nos Estados Unidos da América.” (QUEIROZ, 2015, p. 45), ou seja, com o tempo o cinema se tornou uma mercadoria e ao mesmo tempo por conta de sua expansão tanto dos aparelhos, acabou criando ramificações comerciais, "nos diferentes países, o cinema penetrou nos canais já existentes das antigas formas de diversões tanto em locais fixos - cafés, teatros como em torneios ambulantes." (QUEIROZ, 2015, p. 209), e na capital do Piauí, não foi diferente, pois as primeiras projeções se deram no teatro.

Com a chegada do cinema em 1902 em Teresina, nota-se que diferente das primeiras exibições que ocorreram na França, na capital do Piauí “ o passatempo curioso e raro, atraiu enorme concorrência nas suas sucessivas apresentações, em que se destacaram os quadros animados da paixão de cristo.” (QUEIROZ, 2011, p. 45).Com o avanço da tecnologia e da própria indústria cinematográfica e que se darão muitas mudanças nas projeções, tanto e que nos seus primórdios o que será de destaque, não e somente a projeção, mais sim a

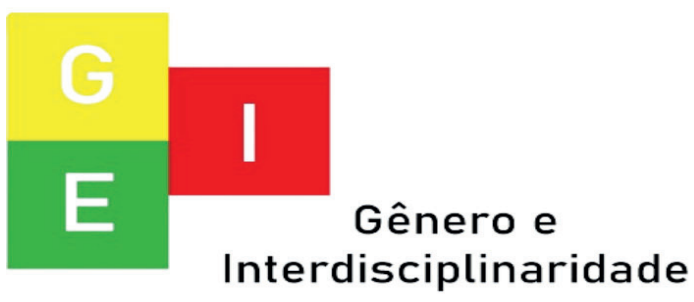


ISSN: 2675-7451

Vol. 02 - n 06- ano 2021

Editora Acadêmica Periodicojs

inserção de novos mecanismos, a própria iluminação, o enredo e a própria perfeição- técnico visual das primeiras fitas.

Através do que foi explicitado até aqui e perceptível imaginar toda a repercussão que a chegada do cinematografo e as primeiras exibições, e em como estes diferentes ambientes sociais daquele período passaram ao visualizar tal invento. Em Teresina, o impacto do cinema não foi diferente. Pois uma diversidade de sentimentos fazia parte da escrita dos literatos.

E os próprios avanços científico-tecnológicos do final do século XIX e começo do século $\mathrm{XX}$ foram alvo de inúmeras reações, especialmente pela Igreja Católica. Inclusive em Teresina, existiam posições positivas e negativas como e o caso das posições expressas por certos segmentos da sociedade teresinense, que eram contrários ao cinema, e estas posições, eram sintetizadas em Elias Martins.

Com o cinematógrafo, esperava-se o propalado apocalipse da moral e da família. $\mathrm{O}$ horror a essa inovação, sintetizado por Elias Martins, interpreta certamente maneiras de pensar e de sentir que não eram isoladas. Como porta-voz dos segmentos mais conservadores da população, o autor expressava muito do assombro dessa sociedade quase rural e ameaçada pela modernidade. (QUEIROZ, 2011, p. $35)$.

Contudo, segundo Queiroz (2011, p.47) o cinema como indústria, mobilizava capitais, que atingiam somas altas, mais nem por isso deixaria de ser associado a educação e um invento

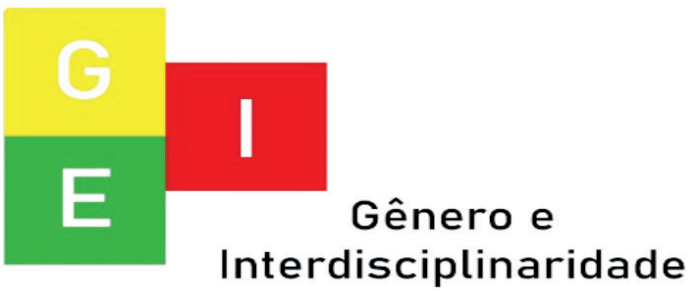


ISSN: 2675-7451

Vol. 02 - n 06 - ano 2021

Editora Acadêmica Periodicojs

moralizador, de uma sociedade moderna, no qual este seria visto como uma diversão do futuro. Mais também, "em outra vertente, o cinema era considerado um invento diabólico, responsável pela crise social, pelo desequilíbrio econômico das famílias, pelas levas de suicídios e crimes do período e por outros comportamentos mórbidos e espetaculares. " (QUEIROZ, 2011, p. 47), mais mesmo com essas posições contrarias, também haviam posições positivas , que são expressas pelo o Higino da cunha e mesmo se mostrava "bastante otimista em relação a essa inovação tecnológica e artística, ele considerava o cinema como diversão do futuro" (QUEIROZ, 2015, p. 46), mais isto somente demonstrava como a sua posição, em relação ao cinema era muito próxima dos redatores da época, que se constituía como "outra verten- te de interpretação do lugar do cinema-que o ligava a modernidade, a novidade, ao refinamento.” (QUEIROZ, 2015, p. 46),ou seja, havia a definição do cinéfilo como habitué-chic. Enquanto que a posição de Elias Martins representava o pensamento conservador e hostil ao novo, que era defendido pela igreja.

Uma passagem que sintetiza bem os posicionamentos desses autores e a seguinte:

Elias Martins, falando em nome dos críticos da nova modalidade de lazer a estigmatiza no livro Fitas, de 1920, responsabilizando-a, no dizer de Higino Cunha, "por todos os males da civilização contemporânea". Para este autor, Elias Martins era excessivo no diagnóstico e ineficaz na terapêutica. Nem é preciso dizer que Higino

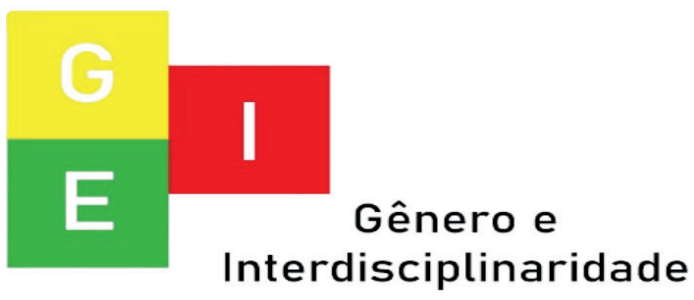


ISSN: 2675-7451

Vol. 02 - n 06 - ano 2021

Editora Acadêmica Periodicojs

Cunha era um dos defensores do cinema, Caracterizando-o como a diversão do futuro. (QUEIROZ, 2011, p. 54)

Na questão da mudança nas práticas sociais, o cinema alterou e ditou novas práticas acerca da própria moda, do como se sentar, como olhar, e até de flertar, "pois sobretudo o cinema (e sobretudo o hall do cinema) era tido como local apropriado para o flerte, diversão moderna e efeito momentâneo e fugidio como o das projeções cinematográficas" (QUEIROZ, 2011, p. 47),e Elias Martins criticava estes namoros no escurinho, pois para ele o espaço onde as fitas eram projetadas, era um lugar erotizado, e que era ali onde aconteciam a iniciação amorosa e sexual. Outra alteração social seria a própria alteração do imaginário da mulher por conta do cinema, e em como está se via, além da mudança na própria visão do Homem, em suas relações amorosas e até suas obrigações domesticas.

Outros impactos do cinema foram nas próprias relações familiares, apor conta do aumento nas próprias despesas familiares:

Além dos preços altos dos bens necessários à manutenção da família, os gatos exagerados no lazer teriam acentuado o desequilíbrio no lazer teriam acentuado o desequilíbrio no orçamento, com crianças e adultos viciados na frequência ao novo sedutor. Disso resultavam maiores solicitações de roupas, e mesmo pequenos roubos para assegurar a ida ao cinema. (QUEIROZ, 2015, p. 54)

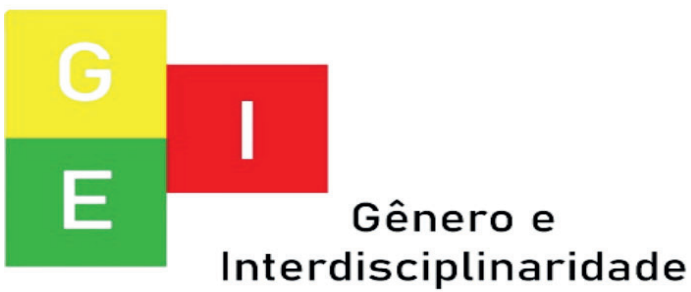


ISSN: 2675-7451

Vol. 02 - n 06 - ano 2021

Editora Acadêmica Periodicojs

Em síntese, o cinema despertou o interesse por onde passou e se firmou, através da sua incorporação ao cotidiano, e isso não se deu somente no mundo, como também na própria Teresina, visto que a própria capital estava inserida no processo de modernização, "os próprios governantes piauienses incorporaram a ideia do novo como moderno" (NASCIMENTO, 2015, p. 329), e nesta perspectiva que estará o cinema inserido, como símbolo da modernidade, é até mesmo se constituindo como um comercio muito rentável ,ou seja, “como mercadoria o cinema não diferiu de outros produtos surgidos no período áureo da expansão capitalista - apropriando-se de seus ganhos e subordinado aos seus limites" (QUEIROZ, 2015, p. 211).

Mais não somente isto, e capaz de explicar o porquê de sua importância ter crescido tanto, e este ter se firmado como a sétima arte, que conhecemos atualmente por seus filmes grandiosos e roteiros muitas vezes bem elaborado:

"Em torno de 1913, e sobretudo nos anos 20, é que atores e atrizes vão estar em destaque nas matérias e passam a constituir-se em referência para o público, que já os associava a trabalhos anteriores. Exemplo de mitos nesses primeiros tempos foram Max Linder e Francesca Bertini, está com uma fama relativamente duradoura, Dezenas de mitos meteóricos foram criados e destruídos pelo o cinema em rápida expansão. (QUEIROZ, 2011, p. 46)

Assim sendo, "o cinema

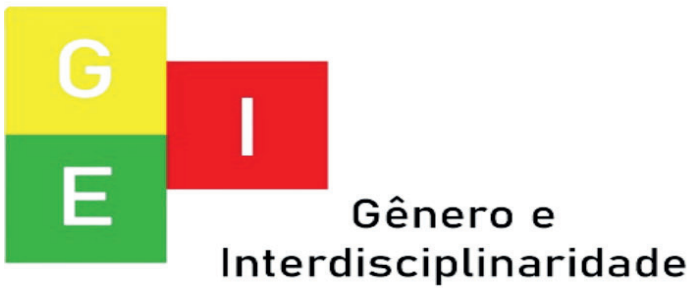


ISSN: 2675-7451

Vol. 02 - n 06 - ano 2021

Editora Acadêmica Periodicojs

é então raro e curioso; os aparelhos são ambulantes e perfazem um circuito regional, indo das capitais ao interior; as máquinas enquanto tais e referidas e chamam a atenção enquanto mecanismos. "(QUEIROZ, 2011, p. 45), e dessa forma, não poderíamos deixar de lado a visão dos literatos, pois estes estavam inseridos nessa sociedade, que passava por uma constante mutação.

Embora cada literato tinha sua própria maneira de ver, sentir e interpretar os novos objetos, que por sua vez este era fruto do desenvolvimento proporcionado pela modernidade, os próprios literatos já eram adultos quando presenciaram essas mudanças, e ora estes vão criticar a Sétima arte, e ora vão também estes se fascinar projetados pela mesma, e esta ai um dos principais motivos do cinema ,ter uma crescente importância, “o apelo constante
, imediato cada vez maior á fantasia e ao sonho.do espectador. É nesta dimensão que reside seu maior diferencial em termos das outras diversões." (QUEIROZ, 2015, p. 211).

Portanto, não podemos esquecer que a própria cidade se constitui como palco de embates, e também de discursos, que por sua vez carregam interesses de um determinada classe, podendo se constituir como um "um processo imaginário de construção de espaço-tempo, na invenção de um passado e de um futuro, a cidade está sempre a explicar o seu presente" (PESAVENTO, 2007, p. 17). Além disso, a área de História e cidade, se constitui uma área riquíssima para pesquisa, não somente para a busca do entendimento das mudanças ocorridas, ao longo do tempo na própria cidade, como também para o entendimento do porque

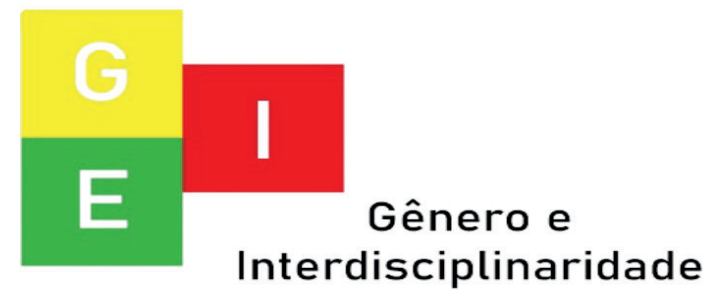


o processo de modernização se constituiu de forma autoritária nas cidades e principalmente nas capitais brasileiras.

\section{REFERÊNCIAS BIBLIO- GRÁFICAS}

CERTEAU, Michel de. A Invenção do cotidiano. 3 eds. Trad. Ephraim Ferreira Alves. Petrópolis: Vozes, 1998. Pag. 169 a 217.

CORRÊA, Roberto Lobato. O espaço urbano. São Paulo: Ática, 1989.

NASCIMENTO, Francisco Alcides D. A cidade sob o fogo: modernização e violência policial em Teresina (1937-1945). 2. ed. Teresina: EDUFPI, 2015. v. 1. $358 \mathrm{p}$.

NASCIMENTO, Francisco Alcides D. Acidade dos sonhos: transformações espaciais e arquitetônicas em Teresina entre 1930 e 1945. Pós-História, v. 13/14, p. 139-158, 2006.

NASCIMENTO, Francisco Alcides Do. Cajuína Cristalina: as transformações espaciais vistas pelos cronistas que atuaram nos jornais de Teresina entre 1950 e 1970. Revista Brasileira de História, v. 27, p. 195-214, 2007.

PESAVENTO, Sandra Jutahy. Cidades visíveis, cidades sensíveis, cidades imaginárias. Revista Brasileira de História, v. 27, n⿳ 53, p..11-23,2007.

QUEIROZ, Teresinha. História, Literatura, Sociabilidades. 2. ed. Teresina-PI: EDUFPI /APL, 2015. v. 1. 234p.

QUEIROZ, Teresinha de Jesus. Os literatos e a República: Clo-

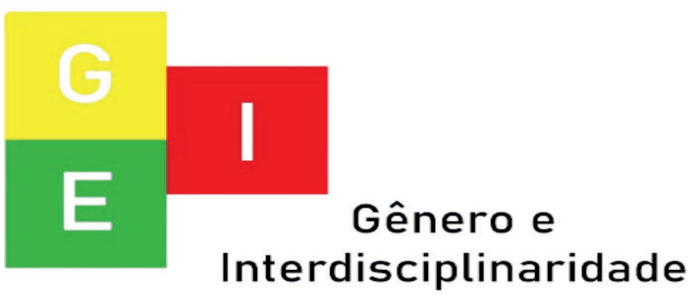


ISSN: 2675-7451

Vol. 02 - n 06 - ano 2021

Editora Acadêmica Periodicojs

doaldo Freitas, Higino Cunha e as tiranias do tempo. 3. ed. Teresina: EDUFPI,2011. p.466.

ROLNIK, Raquel. O que é a cidade. São Paulo: Brasiliense, 1995. (Coleção Primeiros Passos; 203).

SEVCENKO, Nicolau. A capital irradiante: técnica, ritmos e ritos do Rio: In: (Org.) História da vida privada no Brasil República: da Belle Époque a era do Rádio. São Paulo: Companhia das Letras, 1999, p. 514.

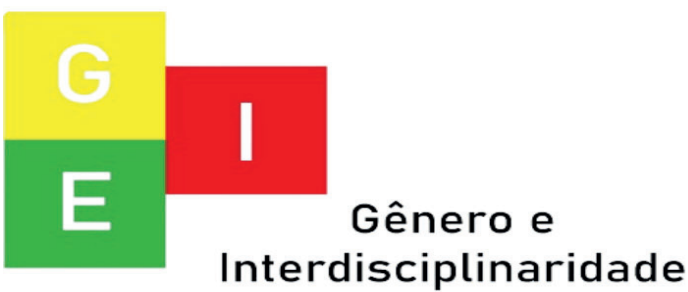

